
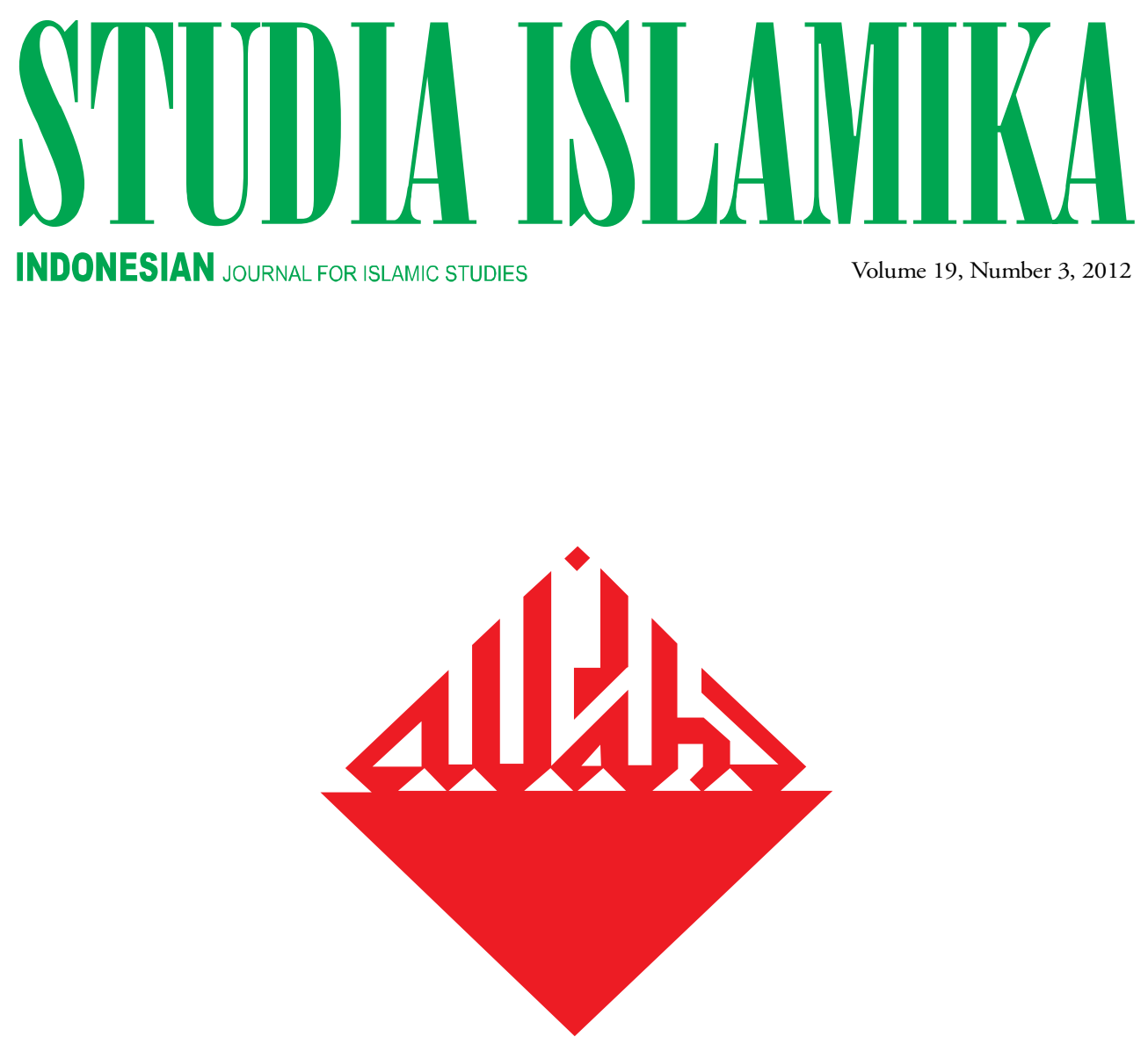

Gender Awareness in Islamic Education:

The Pioneering Case of Indonesia in a Comparison with Pakistan

Ann Kull

Denial, Trivialization and Relegation of Pluralism:

The Challenges of Managing Diversity in Multi-religious Malaysia and Indonesia Azhar Ibrahim

Indonesia's Democratic Venture:

History, Practice and the Challenge Ahead

Bahtiar Effendy \& Mutiara Pertiwi 


\section{SIIIDIA ISLAMIIKA}





\section{SIIDDLA ISLAVIIKA}

Indonesian Journal for Islamic Studies

Vol. 19, no. 3, 2012

EDITORIAL BOARD:

M. Quraish Shihab (UIN Syarif Hidayatullah Jakarta)

Taufik Abdullah (LIPI Jakarta)

Nur A. Fadhil Lubis (IAIN Sumatra Utara)

M.C. Ricklefs (Australian National University, Canberra)

Martin van Bruinessen (Utrecht University)

John R. Bowen (Washington University, St. Louis)

M. Kamal Hasan (International Islamic University, Kuala Lumpur)

Virginia M. Hooker (Australian National University, Canberra)

\section{EDITOR-IN-CHIEF}

Azyumardi Azra

\section{EDITORS}

Saiful Mujani

Jambari

Jajat Burhanudin

Oman Fathurahman

Fuad Jabali

Ali Munhanif

Saiful Umam

Ismatu Ropi

Dina Afrianty

\section{ASSISTANT TO THE EDITORS}

Testriono

Muhammad Nida' Fadlan

ENGLISH LANGUAGE ADVISOR

Melissa Crouch

Simon Gladman

ARABIC LANGUAGE ADVISOR

Nursamad

\section{COVER DESIGNER}

\section{S. Prinka}

STUDIA ISLAMIKA (ISSN 0215-0492) is a journal published by the Center for the Study of Islam and Society (PPIM) UIN Syarif Hidayatullah, Jakarta (STT DEPPEN No. 129/SK/DITJEN/PPG/ STT/1976). It specializes in Indonesian Islamic studies in particular, and Southeast Asian Islamic Studies in general, and is intended to communicate original researches and current issues on the subject. This journal warmly welcomes contributions from scholars of related disciplines.

All articles published do not necessarily represent the views of the journal, or other institutions to which it is affiliated. They are solely the views of the authors. The articles contained in this journal have been refereed by the Board of Editors.

STUDIA ISLAMIKA has been accredited by The Ministry of Education and Culture, Republic of Indonesia as an academic journal (SK Dirjen Dikti No. 56/DIKTI/Kep/2012). 


\section{(C) Copyright Reserved}

\section{Editorial Office:}

STUDIA ISLAMIKA, Gedung Pusat Pengkajian Islam dan Masyarakat (PPIM) UIN Jakarta,

Jl. Kertamukti No. 5, Pisangan Barat, Cirendeu, Ciputat 15419, Jakarta, Indonesia.

Phone: (62-21) 7423543, 7499272, Fax: (62-21) 7408633;

E-mail: studia.islamika@uinjkt.ac.id

Website: www.ppim.or.id

Annual subscription rates from outside Indonesia, institution: US\$ 75,00 and the cost of a single copy is US\$ 25,00 ; individual: US\$ 50,00 and the cost of a single copy is US\$20,00. Rates do not include international postage and handling.

Please make all payment through bank transfer to: PPIM, Bank Mandiri KCP Tangerang Graha Karnos, Indonesia, account No. 101-00-0514550-1 (USD), Swift Code: bmriidja

Harga berlangganan di Indonesia untuk satu tahun,

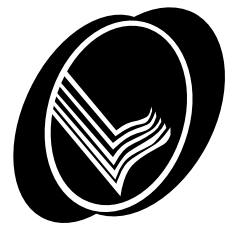
lembaga: Rp. 150.000,-, harga satu edisi Rp. 50.000,-; individu: Rp. 100.000,-, harga satu edisi Rp. 40.000,-. Harga belum termasuk ongkos kirim. 


\section{Table of Contents}

\section{Articles}

397 Ann Kull

Gender Awareness in Islamic Education: The Pioneering

Case of Indonesia in a Comparison with Pakistan

437 Azhar Ibrahim

Denial, Trivialization and Relegation of Pluralism:

The Challenges of Managing Diversity

in Multi-religious Malaysia and Indonesia

477 Bahtiar Effendy \& Mutiara Pertiwi

Indonesia's Democratic Venture:

History, Practice and the Challenge Ahead

513 Ismail Marzuki

Al-Siyāsah al-Qanūnīyah li Hizb al-'Adālah wa al-Rafāhīyah

(Partai Keadilan Sejahtera/PKS) fi al-Fatrah 1998-2004

al-Mīlādī: Dirāsah li Qạ̣īyat Qānūn Idārat al-Zakāh

555 Suprapto

[Kitab Rahasia Hari dan Bintang]:

'Ilm al-Nujūm 'inda al-Muslimīn min Qabīlah Sasak

\section{Book Review}

597 Oman Fathurahman

Memahami Pribumisasi Islam

Melalui Kitab Seribu Masalah

\section{Document}

611 Ismatu Ropi

Regulating Religion in Southeast Asia and the Pacific 
Book Review

\section{Memahami Pribumisasi Islam Melalui Kitab Seribu Masalah}

\section{Oman Fathurahman}

Ronit Ricci, Islam Translated: Literature, Conversion, and the Arabic Cosmopolis of South and Southeast Asia, Chicago and London: The University of Chicago Press, xxii + 316 halaman, 2011.

Abstract: For the time when Islam spread, was adopted and also translated into a variety of traditions and cultures, a comparative studies model such as the one done by Ronit Ricci in Islam Translated has became a very important contribution. The long history of Islamization and conversion has given birth to many Islamic civilizations, including in Southeast Asia. A monolithic view or endless debate related to the origin of sources for the coming of Islam to this region, or the central-periphery perspective that dichotomizes Islam at Mecca and Medina as the 'original' and Islam in other places as 'not pure', has become not relevant anymore. For understanding the phenomena of Islam in Southeast Asia, the author of this book provides discourse on the processes of communication, contacts, networks, diasporas, interaction and transmission that happened in Muslim circles through a variety of different texts in Kitab Seribu Masalah.

Key words: Kitab Seribu Masalah, literary networks, Islamization, cosmopolitan Arabic, Southeast Asia 
Abstrak: Ketika Islam telah tersebar, diadopsi, serta diterjemahkan ke dalam beragam tradisi dan budaya, model kajian komparatif seperti yang dilakukan oleh Ronit Ricci dalam Islam Translated menjadi sangat penting dan kontributif. Sejarah panjang islamisasi dan konversi telah melabirkan banyak peradaban Islam, termasuk di Asia Tenggara. Pandangan monolitik atau perdebatan tak berujung terkait asal-usul sumber datangnya Islam ke wilayah ini, atau perspektif central-peripheral yang mendikotomikan Islam di Mekkah-Madinah sebagai "asli" dan Islam di tempat lainnya sebagai "tidak murni", menjadi tidak lagi relevan. Untuk memahami fenomena Islam di Asia Tenggara, penulis buku ini mendiskusikan proses komunikasi, kontak, jaringan, diaspora, interaksi, dan transmisi yang terjadi di kalangan Muslim melalui beragam tradisi teks Kitab Seribu Masalah.

Kata kunci: Kitab Seribu Masalah, jaringan sastra, islamisasi, kosmopolitanisme bahasa Arab, Asia Tenggara

الحلاصة: مهما تم للاسلام انتشاره وتبنيه وأصبحت تعاليمه مترجمة إلى مختلف فالفالف


Ronit Ricci

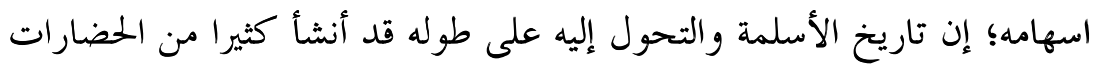

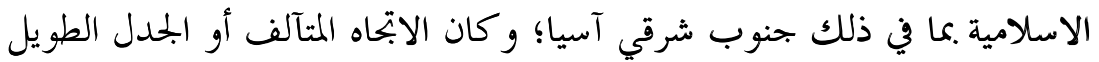

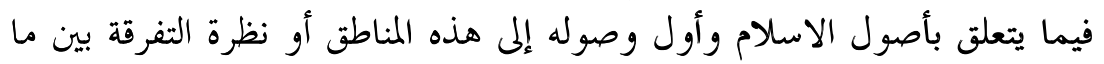

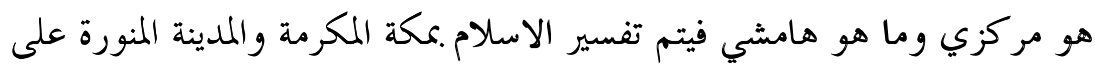

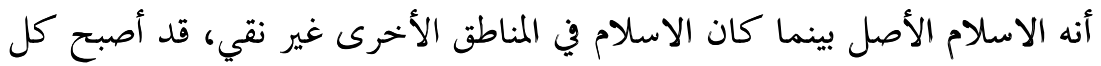

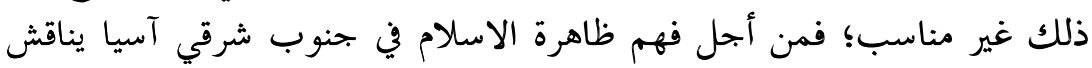



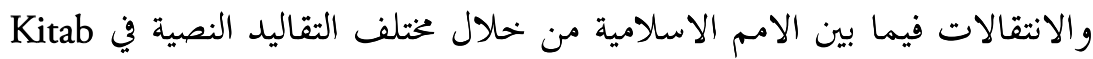
.Seribu Masalah

الكلمات الاسترشادية: Kitab Seribu Masalah، الشبكة الأدبية، اسلمة، عالمية اللغة العربية، جنوب شرقى آسيا. 
$S^{3}$ alah satu persoalan serius yang sering dihadapi oleh mahasiwa atau peneliti yang melakukan kajian tekstual atas sebuah teks adalah kekurangmampuan menempatkan teks yang dikajinya dalam sebuah kerangka teori dan perspektif tertentu yang cocok, serta menempatkan analisisnya dalam konteks yang lebih luas. Padahal, kemampuan memilih kerangka teori yang tepat serta analisis kontekstual itulah salah satu yang dapat menuntun peneliti untuk sampai pada sebuah simpulan tajam dan kontributif dalam bidangnya.

Pada saat yang sama, para peneliti dan mahasiswa pribumi juga sering kurang memanfaatkan sumber-sumber tekstual berupa manuskrip dalam mengkaji fenomena Islam Indonesia. Padahal, sumber-sumber tersebut banyak tersedia dalam berbagai bahasa lokal seperti Melayu, Jawa, Sunda, Bugis-Makassar, Wolio, dan lainnya. ${ }^{1}$ Mereka niscaya tidak akan menemui kesulitan jika mau membaca manuskrip-manuskrip dalam bahasa-bahasa lokal tersebut.

Buku Islam Translated yang ditulis oleh Ronit Ricci dapat menjadi salah satu rujukan contoh ideal bagaimana seyogyanya kajian sebuah teks, dan kajian Islam lokal, dilakukan. Melalui telaah atas transformasi tekstual, konsep, citra, dan genre sebuah teks Arab Kitab Seribu Masalah ke dalam tiga tradisi bahasa, yakni: Jawa, Melayu, dan Tamil, Ricci berhasil menunjukkan bagaimana proses terjadinya metamorfosis bahasa Arab, dan karya sastra Arab, ke dalam tradisi bahasa dan budaya lain, serta membuktikan lahirnya sebuah tradisi Islam baru melalui penerimaan pembaca lokal terhadap teks-teks transformatif tersebut, tanpa mengurangi superioritas tradisi asalnya, Arab.

Ricci membangun kerangka teorinya dengan mengelaborasi teori Sanskrit Cosmopolis yang diperkenalkan oleh Sheldon Pollock menjadi Arabic Cosmopolis dalam konteks penelitiannya. Melalui teori Sanskrit Cosmopolis tersebut, Pollock menelaah bagaimana proses terjadinya transisi penggunaan bahasa Sanskrit yang memiliki status unik baik secara politik maupun budaya, menjadi bahasa dan teks lokal yang muncul di Asia dan Asia Tenggara (h. 13).

Ricci, yang melihat adanya kosmopolitanisme bahasa Arab di wilayah yang sama dengan Pollock, kemudian menyajikan berbagai argumen bahwa bahasa Arab -yang juga diyakini oleh Muslim memiliki status unik sebagai "bahasa Tuhan"- telah menjadi salah satu elemen utama terjadinya kosmopolitanisme Islam di Asia dan Asia Tenggara, di mana Muslim setempat mengadopsi aksara Arab, menjadi aksara Jawi 
dan Pegon misalnya, menyerap berbagai istilah dari bahasa Arab dalam komunikasi sehari-hari, berdoa dengan bahasa Arab, serta membangun peradaban keberaksaraan dan intelektualisme Islamnya melalui bahasa tersebut (h. 14).

Sedikit berbeda dengan para peneliti Islam Asia Tenggara, yang biasanya menonjolkan lahirnya "Islam lokal" dalam proses penerjemahan bahasa dan teks-teks Arab, Ricci justru menggarisbawahi sisi yang lain, yakni bahwa proses lokalisasi, adaptasi, dan pribumisasi yang sedemikian beragam terhadap bahasa dan teks Arab, tidak menghilangkan konteks Arabnya. Justru, melalui tokoh Abdullah bin Salam dalam Kitab Seribu Masalah yang menjadi korpus kajiannya, Ricci menunjukkan bahwa dalam hal konversi dan islamisasi, masyarakat Muslim di Asia dan Asia Tenggara, tetap mengikatkan dirinya pada konteks Arab dalam kisah tersebut, bahkan superioritas bahasa Arab pun semakin diperkuat melalui penggunaan sejumlah kata atau kalimat Arab yang sama sekali dirasa tidak perlu diterjemahkan (h. 129). Lebih jauh, adaptasi teksteks Melayu dan Jawa atas konsep-konsep dan istilah yang berasal dari bahasa Arab telah menghubungkan Muslim di wilayah ini dengan dunia yang lebih luas, Arab-Islam, melalui jaringan keilmuan dan kepercayaan yang diyakini bersama-sama. Fenomena inilah yang ia maksudkan sebagai Arabic Cosmopolis.

Meski demikian, Ricci secara tegas juga mengemukakan adanya perbedaan konsep cosmopolis bahasa Arab yang ia pakai, dengan konsep cosmopolis bahasa Sanskrit yang diperkenalkan oleh Sheldon Pollock tersebut, terutama karena bahasa Arab, berbeda dengan Sanskrit, tersebar di Asia dan Asia Tenggara melalui sebuah agama tertentu, yakni Islam, sehingga memiliki status yang sangat otoritatif dalam menghasilkan teks-teks turunannya dalam bahasa Jawa, Melayu, dan Tamil. Kerangka inilah yang digunakan oleh Ricci untuk menganalisis Kitab Seribu Masalah di keseluruhan bagian buku ini.

\section{Islamisasi dan Literary Networks}

Membaca buku ini, saya serasa diajak untuk memahami kompleksitas persebaran Islam di wilayah Asia dan Asia Tenggara melalui kacamata yang berbeda: sastra. Untuk konteks Asia Tenggara, misalnya, proses islamisasi dan persebaran Islam, khususnya pada abad ke 17 dan 18 yang sering didiskusikan adalah terkait jaringan ulama dengan berbagai karangan kitabnya dalam berbagai bidang keilmuan 
Islam, seperti tașawwuf, fikih, tafsir, hadis, tauhid, dan lain-lain. Topik ini telah mendapat perhatian dan pembahasan yang sangat mendalam dari Azyumardi Azra. ${ }^{2}$

Meski secara substantif Azra juga mengandalkan teks-teks tertulis dalam berbagai bahasa lokal, khususnya Melayu, untuk menggambarkan terjadinya vernakularisasi Islam, akan tetapi mungkin baru Ricci dalam buku ini yang secara spesifik menawarkan penggunaan istilah literary networks (jaringan sastra) untuk menggambarkan saling-silang hubungan Muslim Asia dan Asia Tenggara dengan tradisi dan budaya lain melalui teks-teks kesusastraan. Literary networks yang dimaksud Ricci jelas sangat kompleks dan luas karena mencakup "...shared texts, including stories, poems, genealogies, histories, and treatises on a broad range of topics, as well as the readers, listeners, authors, patrons, translators, and scribes who created, translated, supported, and transmitted them..." (h. 2). Istilah literary networks dapat memperkaya nomenklatur network yang selama ini telah sering dipakai ketika mendiskusikan sejarah awal Islam di Asia Tenggara dalam konteks Sufi, tarekat, perdagangan, atau militer.

Dalam konteks Asia Tenggara, sejumlah sumber terdahulu telah mengkonfirmasi betapa sejarah islamisasi di wilayah ini telah mewariskan khazanah teks-teks tertulis, baik yang bersifat sastra maupun keagamaan, dalam jumlah besar. ${ }^{3}$ Sebagian besar teks-teks Melayu dan Jawa misalnya (saya tidak memiliki pengetahuan terkait khazanah teks-teks Tamil yang dibahas dalam buku ini), memperlihatkan pengaruh Arab dan Islam yang sangat kuat. Telaah komparatif atas teks-teks tersebut niscaya akan memberikan pengetahuan tentang sejarah Islam lokal, kekhasan unsur-unsur lokal dalam sebuah teks dibandingkan unsur dalam bahasa aslinya, serta mengungkap signifikansi proses transmisi dan penerjemahan yang dilakukan oleh aktor Muslim setempat.

Itulah yang berhasil dilakukan dengan sangat baik oleh Ronit Ricci dalam buku ini. Kitab Seribu Masalah menjadi "sekedar" pintu masuk Ricci untuk mengeksplorasi proses dan tradisi penerjemahan serta konversi ${ }^{4}$ yang terjadi di wilayah Asia dan Asia Tenggara. Model kajian Ricci, yang memanfaatkan sebuah teks sastra untuk membaca kompleksitas sejarah dan proses konversi di suatu wilayah ini, jelas menjadi preseden penting dan seharusnya memberikan inspirasi bagi penelitian-penelitian lain dengan memanfaatkan korpus karya sastra lain yang masih banyak tersedia. 
Ricci memang tidak sedang melakukan sebuah penelitian filologis terhadap Kitab Seribu Masalah, sehingga pembaca tidak akan menjumpai edisi teks lengkap karya tersebut dalam buku ini. Bahkan salah satu Kitab Seribu Masalah versi ${ }^{5}$ Arab yang ia rujuk pun bukan berupa manuskrip, melainkan teks cetak yang diterbitkan di Kairo yang berjudul Kitāb Masǟil Sayyidi 'Abdallāh Bin Salām Lin-Nabì (h. 36). Akan tetapi, ketekunan Ricci dalam memperhatikan kata yang digunakan untuk menggambarkan aktivitas penerjemahan dalam setiap tradisi teks yang dikajinya, mengingatkan saya pada tradisi kerja filologis.

Dalam tradisi teks Jawa misalnya, Ricci mengidentifikasi beberapa istilah yang digunakan untuk menggambarkan makna "penerjemahan", seperti njawakaken, binasakaken Jawa, nembangaken, njarwani, njarwakaken, dan jinawakaken. Adapun dalam tradisi Melayu, beberapa istilah yang diidentifikasi Ricci antara lain: dipindabkan, menyalin, menterjemabkan, diceriterakan, dan diperkatakan.

Selain itu, melalui buku ini, para filolog tampaknya juga dapat "belajar" bagaimana membunyikan sebuah teks yang sedang disuntingnya, dengan memilih sebuah kerangka teori yang tepat, dan kemudian melakukan kontekstualisasi untuk menggali makna ekstrinsik teks tersebut. Tentu saja fokus utama sebuah penelitian filologi adalah menyajikan edisi kritis sebuah teks, akan tetapi, dalam beberapa tahun belakangan ini, kecenderungan model kajian filologi tampaknya tidak lagi berhenti pada penyediaan teks "bersih" yang siap baca saja, melainkan juga menghidupkan teks tersebut melalui analisis konteksnya.

Kitab Seribu Masalah sendiri berisi kisah seorang pemuka Yahudi abad ke-7 bernama Abdullah bin Salam, yang mengajukan sejumlah pertanyaan kepada Nabi Muhammad terkait berbagai masalah keagamaan. Singkat cerita, setelah menerima jawaban Muhammad yang sangat meyakinkan, Abdullah bin Salam pun menyatakan memeluk agama Islam.

Selain versi Arab cetakan Kairo, Ricci memanfaatkan sejumlah manuskrip dan edisi teks Kitab Seribu Masalah berbahasa Jawa, Melayu, dan Tamil dengan beragam judul masing-masing, seperti Samud, Seh Ngabdulsalam in Suluk Warna-Warni, Seh Samud, Serat Samud, Suluk Seh Ngabdulsalam, Hikayat Seribu Masalah, dan Äyira Macalā.

Penelusuran Ricci atas sumber-sumber yang terkait dengan Kitab Seribu Masalah juga cukup meyakinkan. Ia misalnya mengutip salah satu sumber Arab paling otoritatif yang menceritakan pertemuan 
Abdullah bin Salam dengan Nabi Muhammad, yakni Sìrāt Rasūl Allāh atau yang juga dikenal sebagai al-Sirah al-nabawiyah karya Muhammad Ibn Ishāa ibn Yasār ibn Khiyār /d. 767 (h. 217).

\section{Arab, Jawa, Melayu, Tamil, dan Parsi: Saling-silang Hubungan Tradisi}

Adalah tidak mungkin untuk memberikan catatan atas keseluruhan bagian buku ini, yang sesungguhnya semuanya sangat menarik dan penting didiskusikan. Perlu beberapa "kacamata" untuk mengulasnya: linguistik, kajian Islam, filologi, sejarah, sastra, teori terjemahan, dan mungkin disiplin ilmu lainnya. Buku ini memang telah menarik sarjana terkait untuk mengulasnya. ${ }^{6}$ Saya pun hanya memilih beberapa bagian saja yang sesuai dengan kacamata yang bisa saya pakai.

Salah satu bagian yang menarik perhatian saya adalah ketika Ricci berupaya merajut saling-silang hubungan satu tradisi dengan tradisi lainnya, dalam hal ini: Arab, Jawa, Melayu, Tamil, dan Parsi, melalui Kitab Seribu Masalah. Apa yang dilakukan Ricci, lagi-lagi, mengingatkan saya pada sebuah aktivitas kritik teks (textual criticism) yang dalam tradisi filologi klasik dikenal dengan metode Stemma, yang pertama kali diperkenalkan oleh sarjana Jerman Karl Lachmann (17931851), dan kemudian diformulasikan secara teoritis oleh Paul Maas (1880-1964). ${ }^{7}$ Metode tersebut meniscayakan beberapa tahap kritik teks yang sangat rigid, seperti recensio (pemilahan teks yang paling dekat dengan aslinya), examinatio (pengujian teks), dan emendation (proses menyisihkan bagian teks yang dianggap "tidak terpercaya"). ${ }^{8}$

Jelas, Ricci tidak sedang menerapkan metode kritik teks Lachman ketika menelusuri keterkaitan antartradisi teks Kitab Seribu Masalah, melainkan "hanya" mengidentifikasi sejumlah informasi internal teks dan terjemahan yang mengindikasikan hubungan satu tradisi teks dengan tradisi teks lainnya. Akan tetapi, dengan melakukan itu, Ricci sadar betul bahwa merajut saling-silang hubungan antartradisi teks itu penting dilakukan untuk menunjukkan adanya keberlangsungan tradisi Arab dalam teks-teks turunannya, yang pada gilirannya akan menguatkan argumennya sendiri tentang Arabic Cosmopolis. Dalam konteks penelitiannya ia mengatakan: "Drawing a link between early Arabic tellings and those in Tamil, Javanese, and Malay is important if we are consider such later tellings as translations - however broadly defined-of an Arabic source." (h. 39-41). 
Kesimpulan Ricci terkait saling-silang hubungan tradisi Arab, Jawa, Melayu, dan Tamil melalui Kitab Seribu Masalah barangkali bisa menjadi topik yang menarik untuk didiskusikan dalam konteks jaringan tradisi keilmuan dan kesusatraan yang lebih luas. Menurutnya, selain petunjuk yang menegaskan bahwa tradisi Jawa juga menerima pengaruh langsung dari tradisi Arab (h. 68), teks Kitab Seribu Masalah juga memberikan informasi penting bahwa tradisi Parsi cukup menonjol sebagai inspirasi munculnya teks yang sama dalam tradisi Tamil dan Melayu (h. 40), meski Ricci buruburu menambahkan bahwa munculnya tradisi Parsi tidak serta merta mengindikasikan adanya hubungan geografis langsung dengan wilayah Persia yang kini bernama Iran tersebut, karena sejak abad ke-17, teks-teks berbahasa Parsi juga banyak diproduksi di India Selatan, wilayah yang terbukti memiliki hubungan langsung, baik secara ekonomi maupun keilmuan, dengan dunia Melayu-Nusantara, khususnya Aceh (h. 132).

Kendati demikian, munculnya motif bahasa Parsi secara konsisten dalam sejumlah besar teks Kitab Seribu Masalah versi Melayu seperti dikemukakan Ricci (h. 131), dapat membuka lagi diskusi tentang sejauh mana pengaruh Syiah, yang sering diidentikkan dengan tradisi Persia tersebut, dalam sejarah kesusastraan Islam Melayu-Nusantara. Seperti diketahui, dibanding teks-teks dengan ideologi Sunni, tidak mudah kiranya menjumpai jejak-jejak Syiah dalam tradisi kesusastraan dan keilmuan Islam di Nusantara, meski sebagian kecil teks dapat memberikan petunjuk. ${ }^{?}$

Selain Jawa, Melayu, dan Tamil yang menjadi korpus penelitian Ricci, cerita Abdullah bin Salam dalam Kitab Seribu Masalah tampaknya juga hadir dan diadopsi dalam tradisi lain, seperti Sunda misalnya. Salah satu naskah versi Sunda berjudul Wawacan Sual Sarebu (SD 167), tersimpan dalam koleksi Perpustakaan Nasional Jakarta, sementara teks serupa (SD 48) dalam koleksi yang sama, didaftarkan sebagai Carios Iblis sareng Nabi Muhammad. ${ }^{10}$ Tidak dilibatkannya tradisi Sunda dalam lingkup pembahasan buku ini menjadi peluang tersendiri bagi peneliti lain yang ingin mengkajinya dalam konteks tradisi Sunda, dan mungkin dengan perspektif yang berbeda.

Gambaran tentang jenis pengaruh yang masuk ke dalam tradisi teks Melayu seperti tercermin dalam Kitab Seribu Masalah semakin menegaskan perbedaannya dengan teks-teks keagamaan dalam tradisi 
yang sama. Seandainya Kitab Seribu Masalah dapat dianggap sebagai representasi dari teks-teks jenis sastra, maka kita bisa mengambil asumsi lebih jauh bahwa pengaruh Parsi sejauh ini memang hanya terlihat dalam teks-teks Melayu jenis sastra, semisal Hikayat Muhammad Hanafyah, Hikayat Amir Hamzah, Hikayat Bayan Budiman, Taj alSalatin, dan lain-lain.

Adapun untuk teks-teks Melayu dan Jawa yang berisi ajaran Islam, seperti fikih, tasawuf, tafsir, dan lain-lain, pengaruh Parsi nyaris tidak terlihat karena tradisi Arab terlalu menonjol. Ungkapan yang lazim ditemui dalam teks-teks Islam Melayu misalnya terdapat dalam pengantar Bidāyat al-mubtadī bi-fadl Allāh al-muhdī ${ }^{11}$ sebagai berikut: "...maka kutaklifkan dan kujawikan risalah ini daripada segala kitab Arabi yang fasahah kepada bahasa Jawi yang baik-baik...". ${ }^{12}$ Ungkapan semacam itu secara eksplisit menegaskan teks dan tradisi Arab lah yang menjadi sumber inspirasinya.

Jika dihubungkan dengan konsep Arabic Cosmopolis yang dikemukakan Ricci dalam buku ini, barangkali fenomena teks-teks keislaman dalam tradisi Melayu dan Jawa lebih jelas memperlihatkan superioritas tradisi Arab. Bahkan seandainya asal sebuah teks Islam tersebut dari India, tradisinya akan sampai ke dunia Melayu melalui tradisi Arab. Contoh atas hal ini adalah teks al-Tuhfah al-mursalah ilá al-Nabi șallá Allāhu 'alayhi wa-sallama yang ditulis oleh seorang ulama India, Fạ̣l Allāh al-Hindī al-Burhānfūrī (w. 1620), ${ }^{13}$ pada tahun 1590, berkaitan dengan doktrin martabat tujuh yang sempat sangat populer di kalangan masyarakat Muslim di dunia Melayu-Nusantara. Berdasarkan sejumlah hasil penelitian terdahulu, teks al-Tuhfah almursalah tidak langsung datang dari India, melainkan melalui kontak intelektual antara Muslim Nusantara dengan para ulama di Mekah dan Madinah. ${ }^{14}$

Teks Arab-India tersebut telah diterjemahkan ke dalam tradisi Melayu oleh 'Abd al-Ṣamad al-Falimbānī menjadi al-Mulakkhaṣ ilá altuhfah, ${ }^{15}$ diterjemahkan ke dalam tradisi Jawa dalam bentuk tembang, ${ }^{16}$ serta melahirkan teks-teks lain berupa komentar (sharh) yang ditulis oleh ulama Nusantara, seperti Sharh al-mawāhib al-mustarsalah 'alá altuhfah al-mursalah yang, berdasarkan salinan naskah koleksi Yayasan Ali Hasjmi, ditulis oleh 'Abd al-Ra' uf ibn 'Ali al-Jawi al-Fansuri (16151693). ${ }^{17}$ 


\section{Khatimah}

Saya ingin mengakhiri tinjauan buku Islam Translated sampai di sini, dan mempersilahkan pembaca yang tertarik mengetahui lebih detil untuk membaca bukunya. Artikel ini merupakan review pertama atas buku tersebut untuk pembaca Indonesia. Meski agak terlambat jika dilihat dari tahun penerbitannya (2011), saya berharap bahwa buku tersebut dapat memberikan inspirasi untuk penguatan kajian Islam Indonesia melalui sumber-sumber primer berupa manuskrip, baik dengan pendekatan filologis, sastra, sejarah, maupun lainnya.

Saya ingin mengakhiri diskusi ini dengan mengatakan bahwa ketika Islam telah tersebar, diadopsi, serta diterjemahkan ke dalam beragam tradisi dan budaya seperti sekarang ini, maka model kajian komparatif seperti yang dilakukan oleh Ronit Ricci dalam Islam Translated menjadi sangat penting dan kontributif. Sejarah panjang islamisasi dan konversi telah melahirkan banyak peradaban Islam, termasuk di Asia Tenggara, baik peradaban tertulis maupun tidak tertulis. Pandangan monolitik atau perdebatan terkait asal-usul sumber datangnya Islam ke wilayah ini, atau perspektif central-peripheral yang mendikotomikan Islam di Mekkah-Madinah sebagai "asli" dan Islam di tempat lainnya sebagai "tidak murni", menjadi tidak lagi relevan.

Tentu saja, ini tidak berarti bahwa pengetahuan tentang bukti-bukti awal islamisasi menjadi tidak penting, justru sumber-sumber semacam itulah yang dapat menuntun kita untuk mengetahui seberapa kuat dan luas jaringan Islam yang terbentuk di suatu wilayah. Hanya saja, seperti dikemukakan Michael Feener, terus-terusan mempertahankan pemahaman monolitik terkait teori asal-usul islamisasi, bukan saja sulit diverifikasi secara empiris, melainkan juga dapat menjebak kita pada perdebatan politik identitas bagi kelompok keagamaan dan etnis tertentu. ${ }^{18}$

Inilah antara lain yang dikembangkan oleh Ronit Ricci dalam Islam Translated. Alih-alih melihat superioritas budaya pra-Islam atau bagaimana Islam datang ke wilayah Asia dan Asia Tenggara, Ricci lebih tertarik untuk melihat proses komunikasi, kontak, jaringan, diaspora, interaksi, dan transmisi yang terjadi di kalangan Muslim melalui beragam tradisi teks Kitab Seribu Masalah, sehingga pemahaman kita tentang Islam di wilayah ini menjadi lebih jernih, lebih kaya, lebih beragam, dan bahkan lebih bisa melihat betapa Islam telah sangat mengakar dalam tradisi dan budaya masyarakat Muslim di luar negeri asalnya. 
Buku ini sangat layak dibaca oleh para pengkaji naskah Nusantara, terutama karena naskah-naskah sastra sejenis yang memperlihatkan pengaruh Islam masih banyak dijumpai. Dalam dunia digital seperti sekarang ini, akses terhadap teks lama pun semakin terbuka, hanya tinggal menunggu dedikasi akademis dan kesungguhan para peneliti saja untuk menggali nilai-nilai luhur yang terdapat dalam khazanah kebudayaan tertulis kita. Semoga. 


\section{Catatan Kaki}

- Artikel ini ditulis pada masa penelitian sebagai Visiting Professor di Research Institute for Languages and Cultures of Asia and Africa, Tokyo University of Foreign Studies (TUFS). Saya mengucapkan terima kasih kepada Professor Koji MIYAZAKI yang telah mengundang saya untuk melakukan riset tersebut.

1. Henri Chambert-Loir dan Oman Fathurahman, Khazanah Naskah: Panduan Koleksi Naskah Indonesia Sedunia, (Jakarta: Yayasan Obor Indonesia, kerja sama dengan EFEO, 1999).

2. Azyumardi Azra, The Origins of Islamic Reformism in Southeast Asia: Networks of Indonesian-Malay and Middle Eastern 'Ulama' in the Seventeenth and Eighteenth Century, (Australia \& Honolulu: Allen \& Unwin and University of Hawai'i Press, 2004).

3. Sir Richard Winstedt, A History of Classical Malay Literature, (Kuala Lumpur: Oxford University Press, 1969); V.I. Braginsky, The System of Classical Malay Literature, (Leiden: KITLV Press, 1993); dan Teuku Iskandar, Kesusasteraan Klasik Melayu Sepanjang Abad, (Brunei: Jabatan Kesusasteraan Melayu, Universiti Brunei Darussalam, 1995).

4. Kata konversi (conversion) secara konsisten dipakai oleh Ricci untuk menggantikan istilah islamisasi (islamization). Menurutnya, dua kata ini harus dibedakan, konversi lebih mengacu pada keputusan seseorang untuk memilih satu agama tertentu, sementara islamisasi merupakan proses perubahan menjadi Islam yang dipengaruhi oleh kompleksitas sosial, budaya, dan sejarah (h. 21). Saya akan menggunakan kedua istilah tersebut dalam tulisan ini.

5. Dalam buku ini, Ricci sebetulnya menghindari penggunaan istilah versi (version) atau varian (variant) yang biasa digunakan dalam konteks filologi. Menurutnya, dua istilah tersebut mengandaikan adanya sebuah teks yang dianggap asli (orisinal), padahal ia tidak menelusuri geneologi tekstual dalam penelitiannya ini. Sebagai gantinya, Ricci secara konsisten menggunakan kata telling, atau "penceritaan" yang dianggapnya lebih cocok digunakan dalam konteks Kitab Seribu Masalah (h. 21).Untuk memudahkan pemahaman dalam bahasa Indonesia, dalam tulisan ini, saya menggunakan kata versi yang merujuk pada maksud kata telling yang dimaksud Ricci.

6. Lihat misalnya tinjauan Francis R. Bradley dalam Indonesia No. 93 (April 2012), h. 217-220.

7. Paul Maas, Textual Criticism, terjemah oleh Barbara Flower (Oxford: Clarendon Press, 1958).

8. S. M. Kater, Introduction to Indian Textual Criticism, (Poona: Deccan College, 1954), h. 30 .

9. L. F. Brakel, Hikayat Muhammad Hanafiyya: A Medieval Muslim-Malay Romance (The Hague: Martinus Nijhoff, 1975). Beberapa manuskrip yang pernah saya jumpai di wilayah Aceh, Cirebon, dan Mindanao mengandung pembahasan tentang syahadat Fatimah, perang Karbala, dan barakah Ali.Teks-teks semacam ini masih membutuhkan penelitian tersendiri jika ingin dihubungkan dengan pengaruh Syiah di Nusantara.

10. T. E. Behrend, (ed.), Katalog Induk Naskah-naskah Nusantara Jilid 4; Perpustakaan Nasional Republik Indonesia, (Jakarta: Yayasan Obor Jakarta bekerjasama dengan EFEO, 1998), h. 308 dan 310.

11. Karya ini sangat populer di dunia Melayu-Nusantara, puluhan manuskripnya dapat ditemukan dalam berbagai koleksi, khususnya koleksi-koleksi di Aceh seperti Museum Negeri Aceh, Zawiyah Tanoh Abee, dan Yayasan Ali Hasjmy (Fathurahman dan Holil 2007:94-97, dan Fathurahman dkk 2010: 127-134). Akan tetapi, ironisnya, identitas pengarang teks ini justru masih belum jelas hingga sekarang. Satu-satunya petunjuk adalah naskah 164/487/Fk-30/TA/2006 koleksi Zawiyah Tanoh Abee, yang dalam 
kolofonnya menyebut: “...karangan Shaykhinā Zayn al-Dīn al-ma'rüf bi Angku Besar Melayu Aceh...”; pun belum diketahui lebih lanjut, siapa dan bagaimana silsilah intelektual nama yang tersebut itu.

12. Kutipan diambil dari MS 07_00782, f. 15v koleksi Museum Negeri Aceh, melalui situs Manuskrip-manuskrip Penginggalan Aceh <http://www.manuscripts-aceh.org/>, diakses 21 Januari 2013.

13. Dia adalah murid Shaykh Wajīh al-Dīn ibn Qāḍi Nasr Allāh 'Alawī Hindī Ahmādabadī (910-998 A.H.), dan Shaykh Muhammad ibn Kathīr al-Dīn Husaynī, atau yang terkenal dengan nama Muhammad al-Ghawth, pengarang kitab al-Jawāhir al-khamsah (Otto Loth, A Catalogue of the Arabic Manuscripts in the Library of the India Office, (London, 1877) Volume I, h. 191-192).

14. Anthony H. Johns, The Gift Addressed to the Spirit of the Prophet, (Canberra: Australian National University, 1965), h. 8-12.

15. Lihat Oman Fathurahman, "Penulis dan Penerjemah Ulama Palembang" dalam Sadur: Sejarah Terjemahan di Indonesia dan Malaysia, ed. Henri Chambert-Loir, (Jakarta: KPG dan EFEO, 2009), h. 1045-1056.

16. Anthony H. Johns, The Gift Addressed, 1965.

17. Oman Fathurahman dan Munawar Holil, Katalog Naskah Ali Hasjmy Aceh, (Jakarta: C-DATS dan PPIM, 2007), h. 156-157.

18. R. Michael Feener, "Introduction: Issues and Ideologies in the Study of Regional Muslim Cultures", in Islamic Connections: Muslim Societies in South and Southeast Asia, eds. R. Michael Feener ad Terenjit Sever, (Singapore: Institute of Southeast Asian Studies, 2009), h. xviii.

Oman Fathurahman, Faculty of Art and Humanities, Syarif Hidayatullah State Islamic University (UIN), Jakarta; Center for the Study of Islam and Society (PPIM), Syarif Hidayatullah State Islamic University (UIN), Jakarta; The Indonesian Association for Nusantara Manuscripts (Masyarakat Pernaskahan Nusantara [Manassa]). 
Indexes

Studia Islamika: 2012

\section{Volume 19, Number 1, 2012}

1. Mohammad Hasan Ansori, Linking Identity to Collective Action: Islam, History and Ethnicity in the Aceh Conflict.

2. Oman Fathurahman, The Roots of the Writing Tradition of Hadith Works in Nusantara: Hidāyāt al-Habīb by Nür al-Dīn al-Rānìrī.

3. Noorhaidi Hasan, Education, Young Islamists and Integrated Islamic Schools in Indonesia.

4. M. Dien Madjid, Tun Sri Lanang fì Masār al-Tärīkh wa 'Aläqatuhu bi Intishār al-Islàm fì Aceh.

5. M. Adib Misbachul Islam, Al-Shaykh Ahmad al-Rifā'ì wa Siyāqūyat al-Sharīáh al-Islamīyah: Dirāsah 'alá Kitab Takhyirah.

6. Azyumardi Azra, Intelektual Muslim Baru dan Kajian Islam.

7. Muhammad Nida' Fadlan, Digitalizing and Cataloging Islamic Manuscripts in Pesantren. 


\section{Volume 19, Number 2, 2012}

1. Hiroko Kushimoto, Islam and Modern School Education in Journal Pengasuh: Review of the Kaum Muda - Kaum Tua Dichotomy.

2. Ali Munhanif, 'Ties that would Divide': Explaining the NU's Exit from Masyumi in 1952.

3. Peter G. Riddell, From Kitab Malay to Literary Indonesian: A Case Study in Semantic Change.

4. Ismawati, Ikhtilāf al-Ṭabìah al-'Ilmīyah al-Islämīyah bayna Manātiq al-Sāhil al-Shimālì wa al-Manātiq al-Dākhilìyah li Jāwah al-Wusțá fi al-Qarn 15-17 al-Mìlādì.

5. Agus Iswanto, Makhtūtat Butuhaning Manusya Mungguhing Sarak: Mi yārīyat al-Islām fì al-Manātiq al-Dākhilīyah bi Jawa.

6. Dick van der Meij, The End of Innocence?

7. Dina Afrianty, Religion in Public Spaces in Contemporary Southeast Asia.

\section{Volume 19, Number 3, 2012}

1. Ann Kull, Gender Awareness in Islamic Education: the Pioneering Case of Indonesia in a Comparison with Pakistan.

2. Azhar Ibrahim, Denial, Trivialization and Relegation of Pluralism: The Challenges of Managing Diversity in Multi-religious Malaysia and Indonesia.

3. Bahtiar Effendy \& Mutiara Pertiwi, Indonesia's Democratic Venture: History, Practice and the Challenge Ahead.

4. Ismail Marzuki, Al-Siyāsah al-Qanūnīyah li Hizb al-Adālah wa alRafähīyah (Partai Keadilan Sejahtera/PKS) fi al-Fatrah 1998-2004 al-Mìlädì: Dirāsah li Qadìyat Qānūn Idārat al-Zakāh.

5. Suprapto, [Kitab Rahasia Hari dan Bintang]: 'Ilm al-Nujūm 'inda al-Muslimin min Qabilah Sasak.

6. Oman Fathurahman, Memahami Pribumisasi Islam Melalui 'Kitab Seribu Masalah'.

7. Ismatu Ropi, Regulating Religion in Southeast Asia and the Pacific. 


\section{Guidelines}

\section{Submission of Articles}

S tudia Islamika, published three times ayear since 1994, is a bilingual journal (English and Arabic) that specializes in Indonesian and Southeast Asian Islamic studies. The aim is to provide readers with a better understanding of Indonesia and Southeast Asia's Muslim history and present developments through the publication of articles, research reports, and book reviews from Indonesian and international scholars alike.

Submission is open to both Indonesian and non-Indonesian writers. Articles will be assessed for publication by the journal's Board of Editors and will be peer-reviewed by a blind reviewer. Only previously unpublished work should be submitted. Articles should be between approximately 10,000-15,000 words. All submission must include a 150-word abstract and 5 keywords.

Submitted papers must conform to the following guidelines: citation of references and bibliography use Harvard referencing system; references with detail and additional information could use footnotes or endnotes using MLA style; transliteration system for Arabic has to refer to Library Congress (LC) guideline. All submission should be sent to studia.islamika@uinjkt.ac.id. 



\section{حقوق الطبعة محفوظة

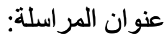

Editorial Office: STUDIA ISLAMIKA, Gedung Pusat Pengkajian Islam dan Masyarakat (PPIM) UIN Jakarta, Jl. Kertamukti No. 5, Pisangan Barat, Cirendeu, Ciputat 15419, Jakarta, Indonesia. Phone: (62-21) 7423543, 7499272, Fax: (62-21) 7408633; E-mail: studia.islamika@uinjkt.ac.id Website: www.ppim.or.id

قيمة الاشتر اك السنوي خارج إندونيسيا:



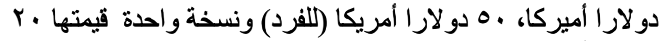

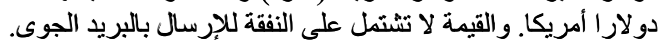

$$
\text { خارج الحساب: }
$$

PPIM, Bank Mandiri KCP Tangerang Graha Karnos, Indonesia account No. 101-00-0514550-1 (USD).

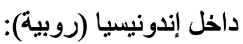
PPIM, Bank Mandiri KCP Tangerang Graha Karnos, Indonesia No Rek: 128-00-0105080-3 (Rp).

قيمة الاشتر اك السنوي داخل إندونيسيا:

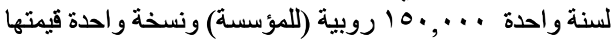

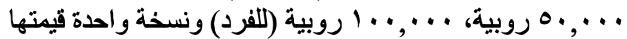

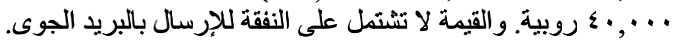

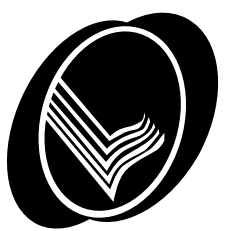




\section{ستوديا إسلاميكا \\ مجلة إندونيسيا للار اسات الإسلامية

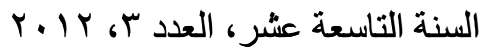

م. قريش شهاب (جامعة شريف هداية الله الإسلامية الحكومية جاكرتا) توفيق عبد الله (المركز الإندونيسي للعلوم) نور أ. فاضل لوبيس (الجلامعة الإسلامية الحككومية سومطرة الشمالية) م.ر. ريكليف (جامعة أستراليا المكومية كانبيرا) مارتين فان برونيسين (جامعة أتريخة)

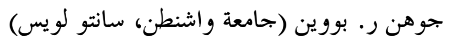


فركنيا م. هو كير (جامعة أستراليا الحكومية كانبيرا)

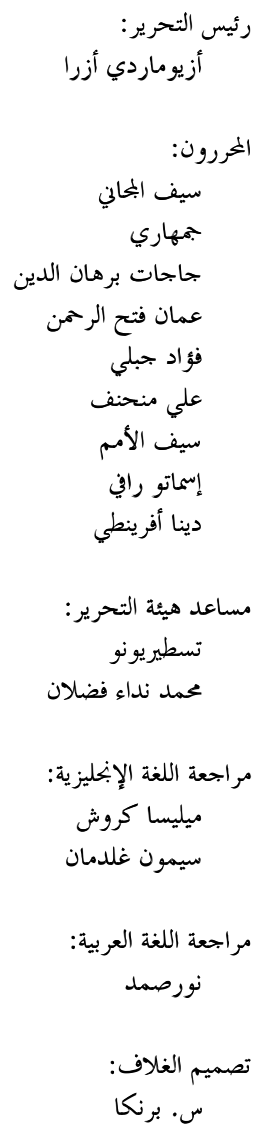

متوديا إسلاميكا (ISSN: 0215-0492) هي بحلة دورية يصدرها مركز البحوث الإسلامية

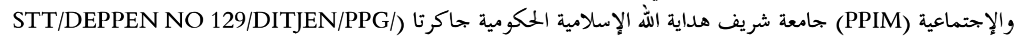

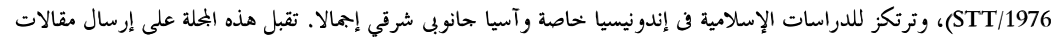

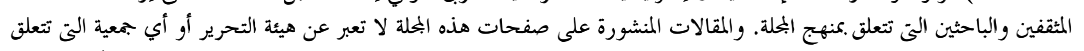

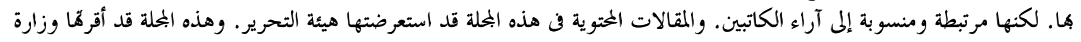
التعليم والثقافة أها بحلة علمية (SK Dirjen Dikti No. 56/DIKTI/ Kep/2012). 

لالتوديا السر||مسيا 




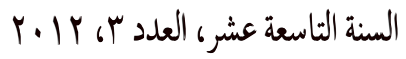

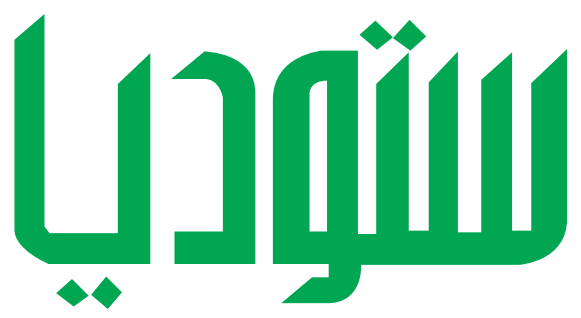

بجلة إندونيسية للدراسات الإسلامية

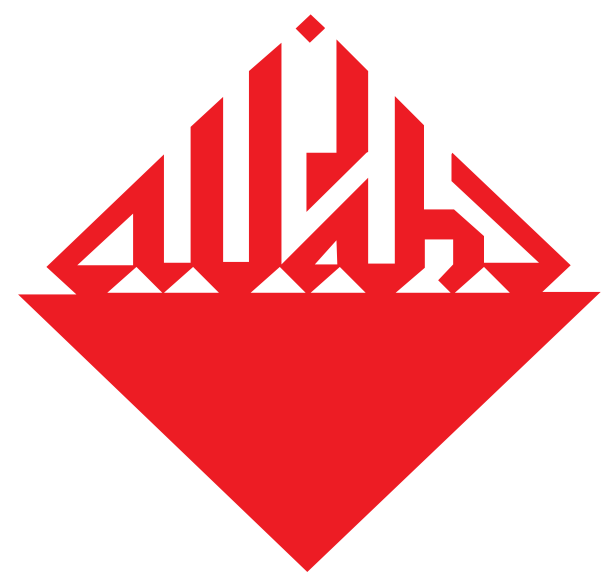

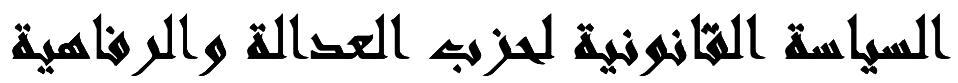

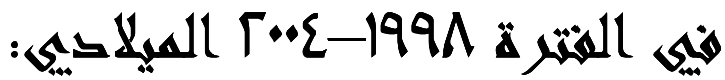

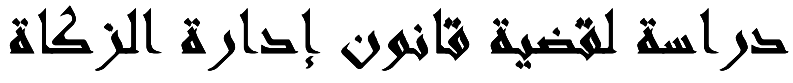
اسماعيل مرزوقي

:[Kitab Rabasia Hari dan Bintang]

على الزجوه لحنق المسلمين هن ثميلة الساساك سو بر ابتو 